\title{
Pengaruh Pemberian Kompres Daun Kubis Terhadap Pembengkakan Payudara Pada Ibu Postpartum
}

\author{
Yopi Suryatim Pratiwi, Sri Handayani, Dian Soekmawati Riezqy Ariendha \\ Email: yopisuryatimpratiwi@gmail.com
}

Program Studi Kebidanan Jenjang D3, STIKes Yarsi Mataram

\begin{abstract}
ABSTRAK
Masalah yang dapat timbul pada masa nifas dan laktasi adalah pembengkakan payudara. Dampak pembengkakan payudara adalah rasa ketidaknyamanan pada ibu berupa nyeri, payudara menjadi keras, demam, bayi sulit menghisap payudara, mastitis, dan abses payudara. Intervensi untuk meringankan gejala pembengkakan payudara sangat dibutuhkan. Beberapa pengobatan secara non farmakologis dapat dilakukan salah satunya yaitu dengan memberikan kompres daun kubis. Studi ini merupakan suatu tinjauan literatur yang mencoba menggali pengaruh pemberian kompres daun kubis terhadap pembengkakan payudara pada ibu postpartum. Hasil review dari 6 penelitian menunjukkan kompres daun kubis efektif dalam mengurangi pembengkakan payudara. Hal ini disebabkan karena daun kubis mengandung asam amino metionin yang berfungsi sebagai antibiotik dan kandungan lain seperti sinigrin (Allylisothiocyanate), minyak mustard, magnesium, Oxylate heterosides belerang yang dapat membantu memperlebar pembuluh darah kapiler sehingga meningkatkan aliran darah untuk keluar masuk melalui daerah tersebut dan memungkinkan tubuh untuk menyerap kembali cairan yang terbendung dalam payudara sehingga dapat mengurangi bengkak payudara.
\end{abstract}

Kata Kunci: Pembengkakan payudara, daun kubis

\begin{abstract}
The problem that can arise in the puerperium and lactation is breast swelling. The impact of breast swelling is a feeling of discomfort in the breast-shaped mother, hardened breasts, fever, the baby is difficult to suck the breasts, mastitis, and breast abscesses. Breast is needed. Some non-pharmacological treatments can be done, one of which is by giving a cabbage leaf compress. This study is a comparative literature that attempts to discuss the comparison of cabbage leaf compresses against breast swelling in postpartum mothers. The results of a review of 6 studies prove that cabbage leaf compresses are effective in reducing breast swelling. This is caused by cabbage leaves containing the amino acid methionine which functions as an antibiotic and other ingredients such as sinigrin (Allylisothiocyanate), mustard oil, magnesium, sulfur heteroside oxides which can help widen the body to absorb the fluid that is blocked in the breast can reduce breast swelling.
\end{abstract}

Keywords: engorgement, cabbage leaves

\section{A. LATAR BELAKANG}

Menyusui merupakan peristiwa alamiah bagi seorang perempuan yang bermanfaat untuk ibu dan bayi. Masalah menyusui yang sering timbul pada masa pasca persalinan dini (masa nifas atau laktasi) adalah pembengkakan payudara (breast engorgement) atau disebut juga bendungan ASI. Pembengkakan payudara merupakan pembendungan air susu karena penyempitan duktus laktiferus atau oleh kelenjar-kelenjar yang tidak dikosongkan dengan sempurna.[1][2]
Payudara pada umumnya akan membesar, keras, dan tidak nyaman karena adanya peningkatan suplai darah ke payudara bersamaan dengan terjadinya produksi air susu. Kondisi ini bersifat normal dan akan berlangsung selama beberapa hari. Namun terkadang pembesaran payudara dapat menimbulkan rasa sakit sehingga ibu tidak leluasa dalam menggunakan bra atau membiarkan benda apapun menyentuh payudaranya. Payudara yang mengalami bengkak akan terasa sakit, panas, nyeri pada 
perabaan, dan tegang.[3] Pembengkakan sedang sering dialami oleh $21-52 \%$ wanita. Sedangkan pembengkakan berat terjadi pada $1-44 \%$. Nyeri sedang dilaporkan dialami oleh $29-68 \%$ wanita, dan 10-33\% wanita mengalami nyeri berat sampai 14 hari, setengahnya memerlukan analgesia untuk meredakan nyeri payudara.[2][4]

Penyebab payudara bengkak diantaranya adalah peningkatan produksi ASI, pelekatan yang kurang baik, keterlambatan menyusui dini, pengeluaran ASI yang jarang, dan adanya pembatasan waktu menyusui.[5] Dampak pembengkakan payudara adalah rasa ketidaknyamanan pada ibu berupa nyeri, payudara menjadi keras, demam, bayi sulit menghisap payudara, mastitis, abses payudara sehingga menyebabkan kegagalan dalam proses laktasi.[6]

Intervensi untuk meringankan gejala pembengkakan payudara sangat dibutuhkan. Beberapa cara untuk mengurangi pembengkakan payudara yaitu secara farmakologis maupun non farmakologis. Penanganan secara non farmakologis dapat dilakukan dengan akupuntur, perawatan payudara tradisional (kompres panas dikombinasikan dengan pijatan), daun kubis, kompres panas dan dingin secara bergantian, kompres dingin, dan terapi ultrasound.[7]

Daun kubis telah digunakan selama berabadabad sebagai obat tradisional untuk berbagai macam penyakit dan menerima banyak perhatian baru dari para profesional laktasi selama 10 tahun terakhir. Kubis atau kol (Brassica Oleracea Var. Capitata) merupakan sayuran ekonomis yang sangat mudah ditemukan di sekitar kita. Kubis kaya akan fitonutrien dan berbagai vitamin seperti vitamin A, C, E, dan kandungan glukosinolate mempunyai aktivitas antikanker. Kubis juga kaya akan kandungan sulfur yang diyakini dapat mengurangi pembengkakan dan peradangan payudara.[8]

Berdasarkan latar belakang di atas, penulis mengambil judul artikel "Pengaruh pemberian kompres daun kubis terhadap pembengkakan payudara pada ibu postpartum"

\section{B. METODE PENELITIAN}

Studi ini merupakan suatu tinjauan literatur (literature review) yang mencoba menggali pengaruh pemberian kompres daun kubis terhadap pembengkakan payudara pada ibu postpartum. Sumber untuk melakukan tinjauan literatur ini meliputi studi pencarian sistematis data base terkomputerisasi (Pubmed, Pro Quest, dan google cendekia) bentuk jurnal penelitian berjumlah 11 penelitian. Penulisan artikel ini menggunakan penulisan daftar pustaka Harvard.

\section{HASIL DAN PEMBAHASAN \\ 1. Hasil}

Beberapa penelitian menunjukkan terdapat pengaruh pemberian kompres daun kubis terhadap pembengkakan payudara pada ibu postpartum. Hal tersebut dapat dilihat pada Tabel 1.

\section{Pembahasan}

Pembengkakan payudara merupakan salah satu masalah yang sering muncul pada ibu post partum [13]. Pembengkakan payudara biasanya terjadi pada hari ketiga sampai hari keempat setelah persalinan. Selama 24 sampai 48 jam pertama sesudah terlihatnya sekresi lakteal, payudara sering mengalami distensi menjadi keras dan berbenjol-benjol. Keadaan ini menggambarkan aliran darah vena normal yang berlebihan dan pengembungan limfatik dalam payudara, yang merupakan prekusor regular untuk terjadinya laktasi. Keadaan ini bukan merupakan overdistensi sistem lakteal oleh air susu.

Pembengkakan payudara terjadi karena ASI yang tidak segera dikeluarkan yang menyebabkan penyumbatan pada aliran vena dan limfe sehingga aliran susu menjadi terhambat dan tertekan ke saluran air susu ibu sehingga terjadinya peningkatan aliran vena dan limfe. Kejadian ini timbul karena produksi ASI yang berlebihan, menyusui bayi terjadwal, bayi tidak menyusu dengan adekuat, posisi menyusui yang salah, atau karena putting susu yang datar/terbenam. Hal ini juga bisa terjadi karena terlambat menyusui dini, perlekatan kurang baik, 
Tabel 1 Hasil Penelitian dari Tinjauan Literatur

\begin{tabular}{|c|c|c|c|}
\hline No. & Penulis & Metode Penelitian & Hasil Penelitian \\
\hline 1. & $\begin{array}{l}\text { Kaur Rajbir, Saini } \\
\text { Parvesh [8] }\end{array}$ & $\begin{array}{l}\text { Disain dalam penelitian } \\
\text { adalah quasi experimental } \\
\text { dengan pretest-posttest } \\
\text { control group design }\end{array}$ & $\begin{array}{l}\text { Pemberian kompres daun kubis dingin yang sudah } \\
\text { didinginkan selama } 20-30 \text { menit sampai suhu daun } \\
\text { kubis mencapai } 18^{\circ} \mathrm{C} \text { digunakan setiap } 2 \text { kali sehari } \\
\text { selama } 3 \text { hari berturut-turut dapat mengurangi } \\
\text { pembengkakan pada payudara sehingga dapat } \\
\text { mencegah komplikasi payudara lebih lanjut. }\end{array}$ \\
\hline 2 & $\begin{array}{l}\text { Tawheda Mohamed } \\
\text { Khalefa El-Saidy, } \\
\text { Reda Mohamed- } \\
\text { Nabil Aboushady } \\
\text { [3] }\end{array}$ & $\begin{array}{l}\text { Disain dalam penelitian } \\
\text { adalah A Quasi- } \\
\text { experimental dengan pre- } \\
\text { posttest group design }\end{array}$ & $\begin{array}{l}\text { Hasil penelitian menunjukkan pemberian kompres } \\
\text { daun kubis pada ibu postpartum efektif untuk } \\
\text { meredakan pembengkakan pada payudara. Skor } \\
\text { engorgement berkurang dari } 3,4 \pm 1,53 \text { menjadi } 1,2 \\
\pm 0,4 \text { setelah intervensi. }\end{array}$ \\
\hline 3 & Zuhana Nina[9] & $\begin{array}{l}\text { Desain dalam penelitian } \\
\text { adalah Parallel Group } \\
\text { Desain }\end{array}$ & $\begin{array}{l}\text { Hasil penelitian menunjukkan skala pembengkakan } \\
\text { payudara setelah diberikan daun kubis dingin } \\
\text { (Brassica Oleracea Var. Capitata) dan perawatan } \\
\text { payudara lebih rendah dari pada sebelumnya. }\end{array}$ \\
\hline 4 & Sharma Rhajni[10] & $\begin{array}{l}\text { Desain dalam penelitian } \\
\text { adalah Quasi } \\
\text { experimental non } \\
\text { Randomized control } \\
\text { group }\end{array}$ & $\begin{array}{l}\text { Hasil penelitian menunjukkan penggunaan daun } \\
\text { kubis efektif dalam mengurangi rasa sakit }(85,9 \% \\
\text { menjadi } 13 \%) \text {, nyeri payudara ( } 80 \% \text { menjadi } 10 \%) \text {, } \\
\text { kemerahan (75\% menjadi } 11 \%) \text {, dan } \\
\text { pembengkakan payudara ( } 88 \% \text { menjadi } 15 \%) \text {. }\end{array}$ \\
\hline 5 & $\begin{array}{l}\text { Joy J , Kharde } \\
\text { SN[11] }\end{array}$ & $\begin{array}{l}\text { Desain dalam penelitian } \\
\text { adalah One group pre test } \\
\text { post test pre experimental } \\
\text { design }\end{array}$ & $\begin{array}{l}\text { Hasil penelitian pada } 30 \text { ibu nifas yang mengalami } \\
\text { bengkak pada payudara didapatkan penggunaan } \\
\text { daun kubis dapat mengurangi rasa sakit dan } \\
\text { pembengkakan pada payudara }(14,86 \% \text { menjadi } \\
1,33 \%) \text {. }\end{array}$ \\
\hline 6 & $\begin{array}{l}\text { Apriani A, } \\
\text { Wijayanti, } \\
\text { Widyastutik D [12] }\end{array}$ & $\begin{array}{l}\text { Desain dalam penelitian } \\
\text { adalah Quasi experimental } \\
\text { study design with non- } \\
\text { randomized control group } \\
\text { pretest posttest }\end{array}$ & $\begin{array}{l}\text { Pemberian terapi daun kubis efektif dalam } \\
\text { mengurangi pembengkakan pada payudara dimana } \\
\text { skor pembengkakan mengalami penurunan setelah } \\
\text { diberikan kompres daun kubis yaitu } 15,17 \text { menjadi } \\
11,67 \text {. }\end{array}$ \\
\hline
\end{tabular}

atau mungkin kurang seringnya ASI dikeluarkan[3].

Six-points engorgement scale (SPES)[3]

1 : Halus

2 : Terdapat perubahan pada payudara

3 : Payudara terasa keras/tegang dan tidak sakit

4 : Payudara terasa keras/tegang dan mulai terasa nyeri pada payudara

5 : Payudara terasa keras/tegang dan terasa sakit

6 : Payudara terasa sangat keras/tegang dan terasa sangat sakit

Bengkak pada payudara menjadi hal yang serius jika di abaikan, sehingga perlunya intervensi untuk meringankan gejala pembengkakan payudara. Pemberian kompres daun kubis merupakan salah satu cara penanganan secara non farmakologis untuk mengurangi bengkak payudara.
Kubis mengandung asam amino metionin yang berfungsi sebagai antibiotik dan kandungan lain seperti sinigrin (Allylisothiocyanate), minyak mustard, magnesium, Oxylate heterosides belerang yang dapat membantu memperlebar pembuluh darah kapiler sehingga meningkatkan aliran darah untuk keluar masuk melalui daerah tersebut dan memungkinkan tubuh untuk menyerap kembali cairan yang terbendung dalam payudara tersebut. Selain itu daun kubis juga mengeluarkan gel dingin yang dapat menyerap panas yang ditandai dengan klien merasa lebih nyaman serta daun kubis menjadi layu/matang setelah penempelan [13][14].

Penanganan pembengkakan payudara menggunakan daun kubis:[3]

1) Pilih daun kubis hijau yang masih segar 
2) Daun kubis hijau diambil secara utuh perlembar, usahakan tidak robek

3) Daun kubis dapat digunakan dalam kondisi dingin (didinginkan dalam freezer sekitar 20-30 menit atau sampai suhu daun $18^{\circ} \mathrm{C}$ ) atau pada suhu kamar.

4) Keluarkan dan siapkan daun kubis yang sudah dingin dari freezer

5) Letakkan daun kubis dingin di atas payudara

6) Tutupi semua area payudara yang bengkak dan kulit yang sehat

7) Kompres payudara selama 15-20 menit atau sampai daun kubis tersebut layu (dapat dilakukan didalam bra)

8) Lakukan 2 kali sehari selama 3 hari berturut-turut
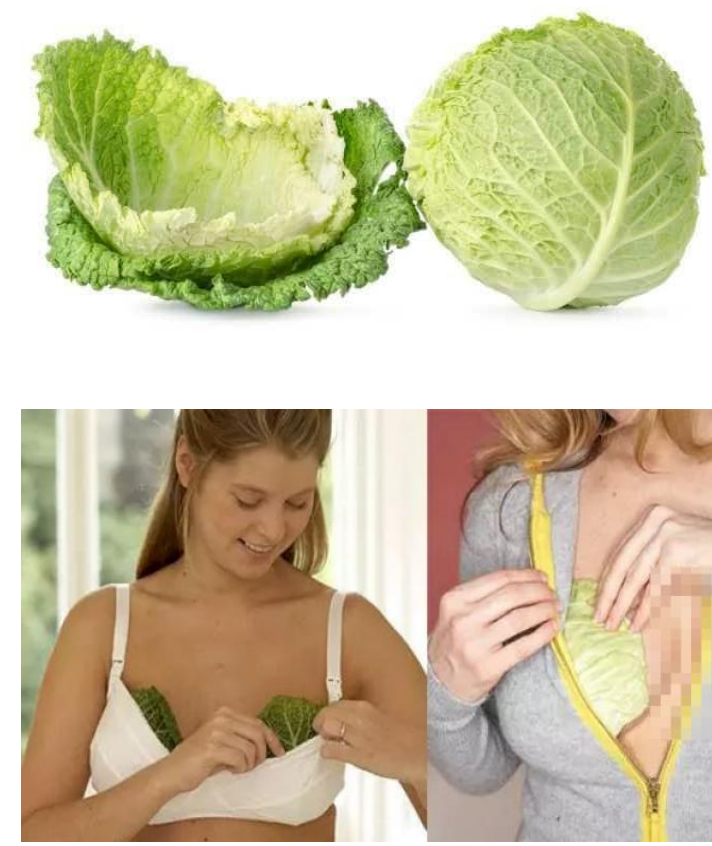

Gambar 2. Penggunaan Daun Kubis

Beberapa hasil penelitian yang membuktikan penggunaan daun kubis efektiv digunakan untuk mengurangi pembengkakan pada payudara. Song Ji-Ah dan Hur Myung Haeng menjelaskan hasil Systematic Review dari 12 artikel, daun kubis efektif dalam mengurangi rasa sakit, nyeri, dan bengkak pada payudara.[15] Penelitian lain oleh Sharma (2018) menunjukkan penggunaan daun kubis juga dapat mengurangi rasa sakit $(85,9 \%$ menjadi $13 \%)$, nyeri payudara ( $80 \%$ menjadi $10 \%$ ), kemerahan (75\% menjadi 11\%), dan pembengkakan payudara (88\% menjadi 15\%), serta dapat memperpanjang durasi menyusui. [10]

Bidan dapat memainkan peran penting dalam deteksi dini dan manajemen pembengkakan payudara yang tepat untuk menjaga kesehatan wanita dan meningkatkan keberhasilan menyusui.

\section{KESIMPULAN}

Kompres daun kubis yang mengandung asam amino metionin, sinigrin (Allylisothiocyanate), minyak mustard, magnesium, Oxylate heterosides belerang efektif mengurangi pembengkakan payudara, sehingga memperpanjang durasi menyusui dan meningkatkan keberhasilan menyusui.

\section{E. UCAPAN TERIMA KASIH}

Terima kasih kami ucapkan kepada para editor dan reviewer yang telah berkontribusi dengan meluangkan waktu dan mencurahkan pikirannya demi terbitnya artikel literature review ini. Saran dan kritik selalu kami harapkan demi tercapainya manfaat dari penerbitan artikel ini.

\section{DAFTAR PUSTAKA}

[1] Prawirohardjo, Sarwono Ilmu kebidanan. Yayasan bina Pustaka. Jakarta. 2014;700.

[2] Cunningham. William Obstetri. EGC. Jakarta. 2013;744.

[3] Tawheda Mohamed Khalefa El-Saidy, Reda Mohamed-Nabil Aboushady. Effect of two different nursing care approaches on reduction of breast engorgement among postnatal. Women. Journal of Nursing Education and Practice. 2016;6(9):1-11.)

[4] Myles. Buku Ajar Kebidanan.EGC. Jakarta. 2010; 629

[5] Wambach K, Riordan J. Breastfeeding and Human Lactation. Burlington, MA: Jones \& Bartlett Learning; 2014.

[6] Saifuddin, Abdul Bari. Panduan Praktis pelayanan kesehatan maternal neonatal. yayasan bina pustaka sarwono prawirohardjo. Jakarta. 2008; 262; N-27 
DAN Myles. Buku Ajar Kebidanan.EGC. Jakarta. 2010; 629.

[7] De Sousa L, Haddad ML, Nakano AM, Gomes FA. Non pharmacologic treatment to relieve breast engorgement during lactation: an integrative literature review. Rev Esc Enferm USP. 2012 Apr;46(2):472-9.

[8] Kaur R, Saini P. A Quasi-experimental Study on Effectiveness of Cabbage Leaves Application for Breast Engorgement in Postnatal Mothers at Selected Hospitals, Amritsar, Punjab, India. Current Trends in Diagnosis and Treatment. 2017;1(2):72-5.

[9] Zuhana, Nina. Perbedaan efektifitas da un kubis dingin (Brassica Oleracea Var. Capitata) dengan perawatan payudara dalam mengurangi pembengkakan payudara (Breast Engorgement) di Kabupaten Pekalongan. Jurnal Ilmiah Bidan. 2017;2(2):1-6.).

[10] Sharma Rajni. Effectiveness of Chilled Cabbage Leaf Application on Breast Engorgement among Post Partum Women's. Journal of medical science and clinical research. 2018;6(6):878-82.

[11] Joy J , Kharde SN. A study to evaluate the effectiveness of chilled cabbage leaves application for relief of breast engorgement in volunteered postnatal mothers who are admitted in maternity ward of selected hospital in belgaum. Int $\mathbf{J}$ Biol Med Res.2016;7(3):5655-5659.

[12] Apriani A, Wijayanti, Widyastutik D. Efektivitas penatalaksanaan kompres daun kubis (brassica oleracea var. capitata) dan breast care terhadap pembengkakan payudara bagi ibu nifas. Maternal. 2018;2(4): 238-43.

[13] Salgaonkar, Rajashree. Chilled Cabbage Leaves: The Possible Remedy for Breast Engorgement. International Journal of Nursing and medical investigation. 2019;4(1):1-3.

[14] Thomas T, Devi ES, George LS. Efficacy of Evidence Based Practice (EBP) Guideline to Prevent and Treat Breast Engorgement among Post Caesarean Mothers in Selected Hospital in Mangalore. NUJHS. 2017;7(1):21-4.

[15] Song Ji-Ah, Hur Myung Haeng. A Systematic Review of Breast Care for Postpartum Mothers. Korean J Women Health Nurs. 2019;25(3):258-272. 